\title{
Endovascular repair of the ascending aorta in patients at high risk for open repair
}

\author{
Prashanth Vallabhajosyula, MD, MS, Jean-Paul Gottret, MD, Joseph E. Bavaria, MD, \\ Nimesh D. Desai, MD, PhD, and Wilson Y. Szeto, MD
}

Objective: Although endovascular repair has been widely adopted for treatment of descending thoracic aortic pathologies, its role in ascending aortic pathologies remains undefined. We reviewed our experience with endovascular repair of ascending aortic pathologies in patients facing high or prohibitive risk with open surgical treatment.

\begin{abstract}
Methods: From 2007 to 2013, 6 patients (aged 16-90 years) underwent endovascular repair (pseudoaneurysm, $\mathrm{n}=4$; acute type A aortic dissection, $\mathrm{n}=2$ ). Their records were retrospectively reviewed.

Results: All patients had extensive comorbidities or anatomic features making an open surgical approach high risk. Three cases were done on an emergency basis (aortic dissection, $\mathrm{n}=2$; ruptured pseudoaneurysm, $\mathrm{n}=1$ ). Ascending aortic access was obtained through transapical $(n=4)$, transfemoral $(n=1)$, and left common carotid artery $(\mathrm{n}=1)$ approaches. Cook Zenith TX2 $(\mathrm{n}=4)$, Cook EVAR iliac limb $(\mathrm{n}=1)$, and Amplatzer occluder $(\mathrm{n}=1)$ devices were used, with 3 patients requiring more than 1 stent-graft. Stent-graft lengths ranged from 55 to $81 \mathrm{~mm}$; diameters ranged from 22 to $40 \mathrm{~mm}$. Technical success was achieved in 5 cases $(83 \%)$; 1 patient (type A dissection) had an intraoperative endoleak not amendable to further endovascular repair. In-hospital and 30-day mortalities were zero. One patient sustained a minor stroke, which reversed completely. Stay ranged from 5 to 15 days. On follow-up, 1 patient (type A dissection) had an endoleak at 12 months. Two patients died of nonaortic causes at 6 and 27 months after endovascular repair.
\end{abstract}

Conclusions: Endovascular repair of ascending aortic pathology is feasible in patients facing high risk with open surgery, with promising early results. Technical challenges remain in adapting current endovascular technology to ascending aortic pathologies, particularly type A aortic dissection. (J Thorac Cardiovasc Surg 2015;149:S144-50)

Results of open surgical management of ascending aortic pathologies have continued to improve during the last decade, with decreasing morbidity and mortality. Certain patients with significant anatomical challenges and extensive comorbidities, however, remain at high risk if undergoing open surgical repair. Although endovascular repair techniques for descending thoracic aortic pathology have revolutionized surgical management strategies and provided a treatment for these high-risk patients, their use in treating aortic arch and ascending aortic pathologies has remained limited. Complexities in the anatomy of the

From the Division of Cardiovascular Surgery, Department of Surgery, University of Pennsylvania Medical Center, Philadelphia, $\mathrm{Pa}$.

Disclosures: Joseph E. Bavaria reports work as an investigator and consultant for Medtronic and Gore. Wilson Y. Szeto reports work as an investigator for Medtronic and Gore and consultant work for Medtronic and Bolton Medical. Nimesh D. Desai reports consulting work for Medtronic and St. Jude. All other authors have nothing to disclose with regard to commercial support.

Read at The American Association for Thoracic Surgery Aortic Symposium, New York, New York, April 24-25, 2014.

Received for publication April 29, 2014; revisions received July 22, 2014; accepted for publication July 25, 2014; available ahead of print Sept 11, 2014.

Address for reprints: Wilson Y. Szeto, MD, University of Pennsylvania Medical Center, Penn Presbyterian Medical Center, 51 N 39th St, Heart and Vascular Pavilion 2A, Philadelphia, PA 19104 (E-mail: Wilson.szeto@uphs.upenn.edu). $0022-5223 / \$ 36.00$

Copyright (C) 2015 by The American Association for Thoracic Surgery

http://dx.doi.org/10.1016/j.jtcvs.2014.07.063 aortic root, ascending aorta, and the aortic arch-and the close spatial relationships between these vital structuresrepresent major obstacles to endovascular therapy of the proximal aorta. In this report, we review our institutional outcomes with the use of endovascular repair techniques for ascending aortic pathologies in patients facing high risk with conventional open surgical repair.

\section{MATERIALS AND METHODS}

Institutional review board approval from the University of Pennsylvania was obtained for this retrospective review.

\section{Patients}

From 2007 to 2012, a total of 6 consecutive patients underwent endovascular repair because various factors rendered open surgical approach of high or prohibitive risk. Patient age ranged from 16 to 90 years (mean, $68 \pm 23$ years). The ascending aortic pathologies included type A aortic dissection $(n=2)$ and pseudoaneurysm formation from previous thoracic operations $(n=4)$. In all cases, informed consent was obtained. Two patients with type A aortic dissection underwent repair on an emergency basis, 1 patient with innominate artery pseudoaneurysm underwent urgent repair, and 3 patients with pseudoaneurysm underwent repair on an elective basis.

\section{Diagnostic Workup}

All patients underwent computed tomographic angiography of the chest, abdomen, and pelvis for evaluation of the ascending aortic 

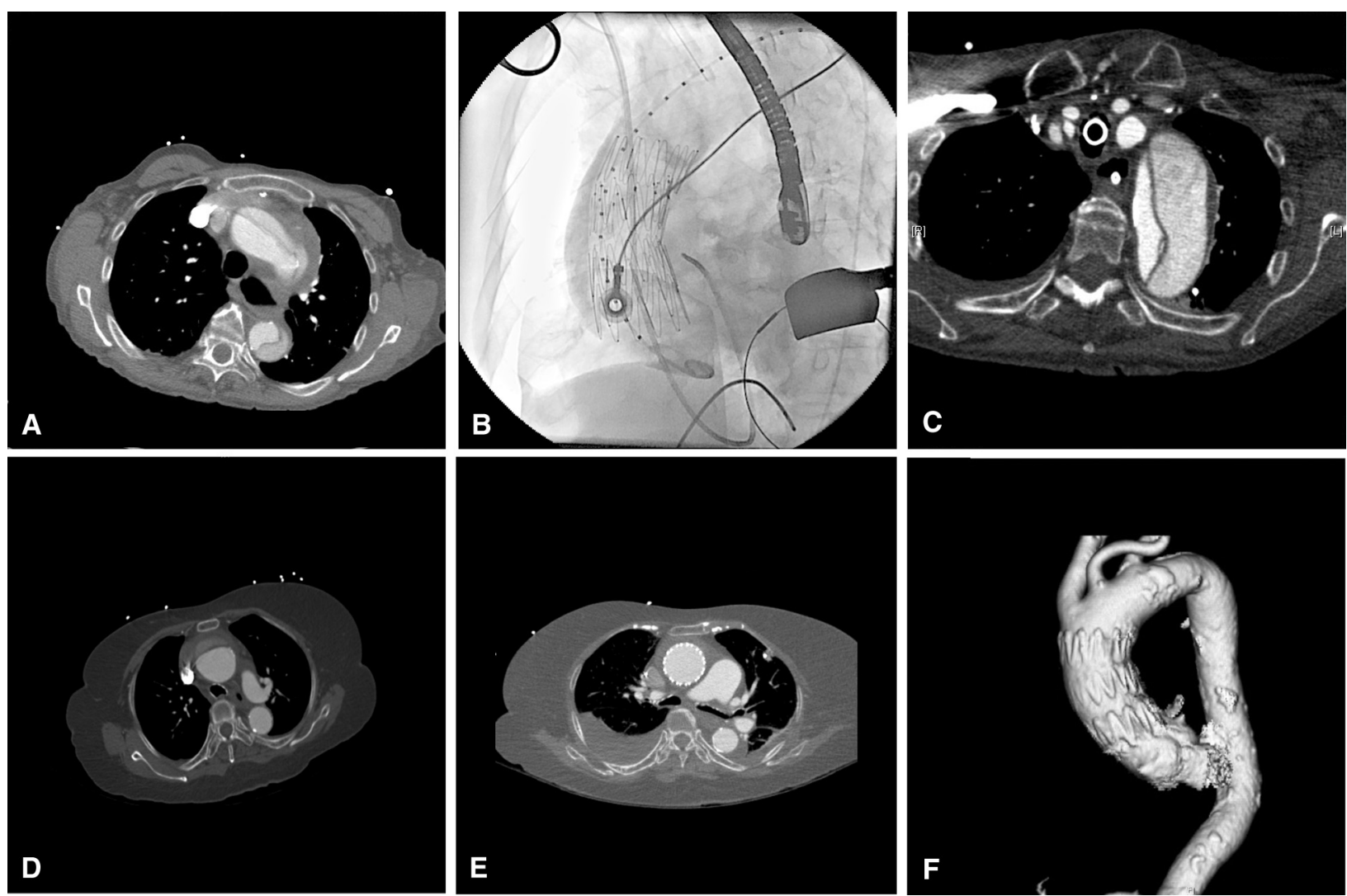

FIGURE 1. Imaging for the 2 patients with acute type A aortic dissection is shown. A, Patient 1 was seen with innominate artery occlusion and cerebral malperfusion and pressure-dependent left hemiplegia. B, A Zenith TX2 distal extension graft was deployed through a transapical approach. C, Postoperative computed tomography, showing restored innominate artery flow (with clinical resolution of hemiplegia) but a persistent proximal endoleak. D, Patient 2 had Childs $\mathrm{C}$ cirrhosis and was seen with a contained rupture of an acute type A aortic dissection. E, Postoperative computed tomography demonstrating that a good seal, with no endoleak, was achieved with the ascending aortic stent-graft. F, Three-dimensional aortic model showing proximal and distal landing zones of the ascending graft, without coverage of the aortic root or arch vessels.

pathology, sizing of the endograft, and planning of the surgical access. In 2 patients with pseudoaneurysm from previous coronary artery bypass grafting procedures, cardiac catheterization was performed. In the 3 elective cases, preoperative transthoracic echocardiography was also performed.

\section{Operative Techniques and Surgical Approach}

All procedures were performed in the hybrid operating room, with the cardiac perfusion team on stand-by and the cardiac anesthesia team monitoring with transesophageal echocardiography. Rapid ventricular pacing was performed in selected cases to minimize pulsatility and movement of the endografts during deployment. A transapical approach was used in 4 cases, a transfemoral approach in 1 case, and a left common carotid artery approach in 1 case. A transapical approach was chosen if femoral artery access was inadequate or if the length of the endograft delivery system was insufficient to reach the ascending aorta.

For the transapical approach, a small left anterior thoracotomy was performed to expose the left ventricular apex. Systemic heparinization (typically 5000 units, intravenously) was given to achieve an activated clotting time greater than 250 seconds. A 14-gauge needle was used to puncture the left ventricular apex between 2 horizontal, 2-0 Prolene (Ethicon, Inc, Somerville, NJ) mattress stitches. Under echocardiographic and fluoroscopic guidance, a guidewire was advanced through the ascending aorta and into the descending thoracic aorta, with care taken to avoid the mitral valve chordal apparatus. In the 2 dissection cases, transesophageal echocardiography was also used to confirm placement of the guidewire in the true lumen (Figure 1). Appropriately sized endografts, as determined by preoperative computed tomographic angiography, were then advanced into the ascending aorta over the guidewire and deployed under fluoroscopic and echocardiographic guidance. The apical sutures were secured to achieve hemostasis.

For the transfemoral approach, a common femoral artery was accessed percutaneously, and the contralateral femoral artery was accessed for placement of a pigtail catheter, used for diagnostic angiography. In a case requiring closure of a pseudoaneurysm at the aortic anastomosis of an occluded saphenous vein graft, an Amplatzer device (AGA Medical Corporation, Plymouth, Minn) was deployed to occlude the pseudoaneurysmal sac (Figure 2, $C$ and $D$ ).

The left common carotid artery approach was chosen for a pediatric patient because the endograft delivery system was too short to access the ascending aorta through a femoral approach, and an EVAR iliac limb extension (Zenith $22 \times 55 \mathrm{~mm}$; Cook Medical Inc, Bloomington, Ind) was used because of the small size of the aorta (Figure 2, $G$ and $H$ ). The patient had undergone a mediastinal tracheostomy and innominate artery ligation, because extensive radiation damage had resulted in an innominate artery pseudoaneurysm. Cardiopulmonary bypass with cannulation of the distal left carotid artery maintained cerebral perfusion, permitting temporary occlusion of the proximal left carotid artery for endograft deployment. Technical details of this procedure have been previously described. 

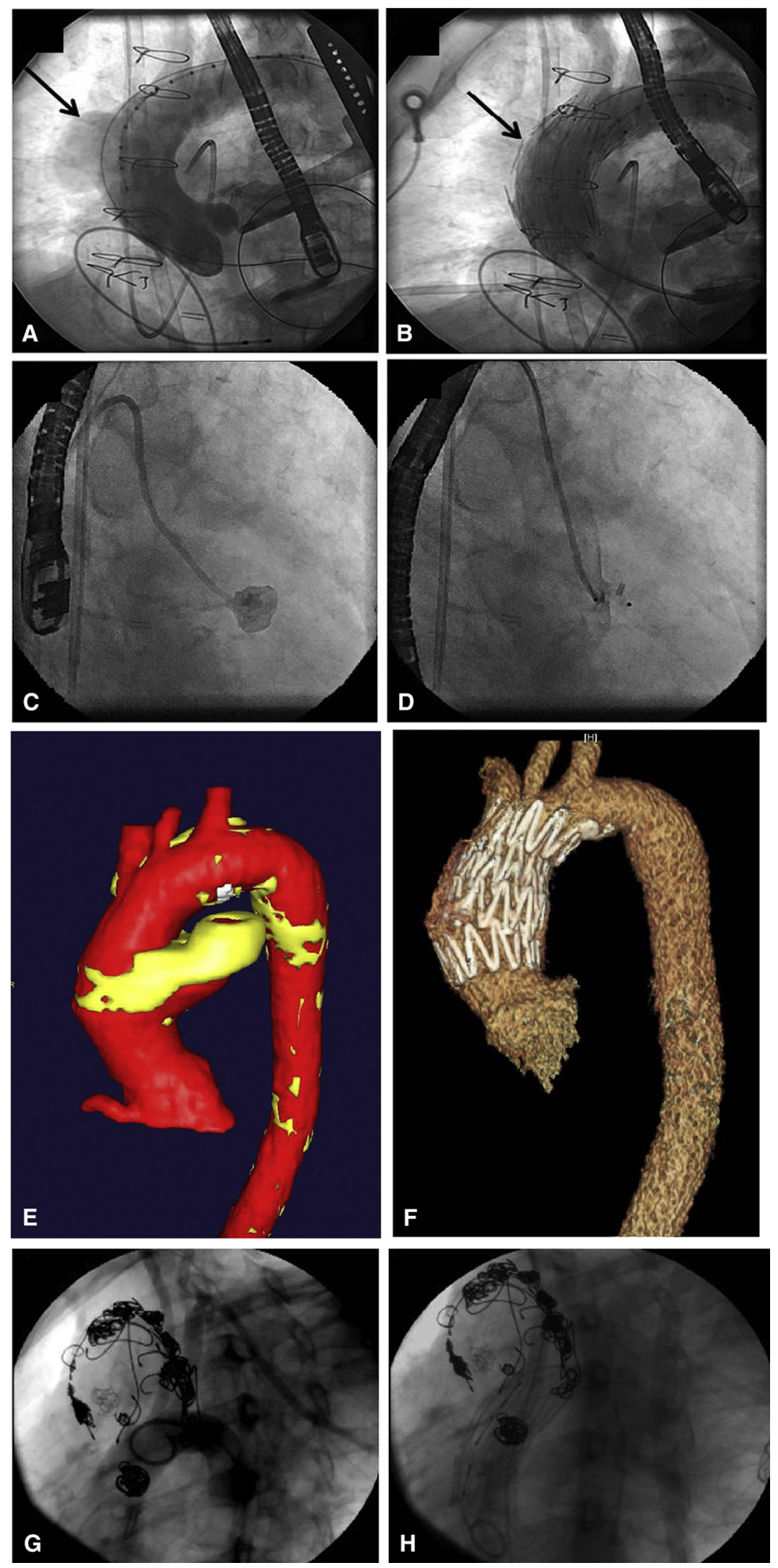
TABLE 1. Patient demographic and preoperative characteristics

\begin{tabular}{|c|c|c|c|c|c|c|c|}
\hline Patient & $\begin{array}{c}\text { Age } \\
(y)\end{array}$ & Sex & Previous surgery & Aortic pathology & $\begin{array}{c}\text { Complication on } \\
\text { presentation }\end{array}$ & Status & Comorbidities \\
\hline 1 & 90 & Female & None & $\begin{array}{l}\text { Acute type A aortic } \\
\text { dissection }\end{array}$ & $\begin{array}{l}\text { Cerebral } \\
\text { malperfusion }\end{array}$ & Emergency & $\begin{array}{l}\text { Extreme frailty, hypertension, } \\
\text { stroke, coronary artery disease, } \\
\text { advanced age }\end{array}$ \\
\hline 2 & 78 & Female & None & $\begin{array}{l}\text { Acute type A aortic } \\
\text { dissection }\end{array}$ & Rupture & Emergency & $\begin{array}{l}\text { Hypertension, chronic hepatitis B, } \\
\text { cirrhosis (Child C), hepatocellular } \\
\text { carcinoma }\end{array}$ \\
\hline 3 & 80 & Female & $\begin{array}{l}\text { Coronary artery bypass } \\
\text { graft } \times 3 \text {, multiple } \\
\text { reexplorations }\end{array}$ & $\begin{array}{l}\text { Pseudoaneurysm from } \\
\text { venous graft } \\
\text { anastomosis }\end{array}$ & Growth & Elective & $\begin{array}{l}\text { Recurrent Pseudomonas and } \\
\text { Klebsiella sternal infections, } \\
\text { chronic sternal osteomyelitis }\end{array}$ \\
\hline 4 & 78 & Male & $\begin{array}{l}\text { Coronary artery bypass } \\
\text { graft } \times 5\end{array}$ & $\begin{array}{l}\text { Pseudoaneurysm from } \\
\text { clamp site injury }\end{array}$ & Growth & Elective & $\begin{array}{l}\text { Hypertension, diabetes, chronic renal } \\
\text { failure, coronary artery disease, } \\
\text { congestive heart failure, coronary } \\
\text { graft failure } \times 4\end{array}$ \\
\hline 5 & 54 & Male & $\begin{array}{l}\text { Combined heart and } \\
\text { bilateral lung transplant }\end{array}$ & $\begin{array}{l}\text { Pseudoaneurysm from } \\
\text { donor-recipient } \\
\text { anastomosis }\end{array}$ & Growth & Elective & $\begin{array}{l}\text { Hypertension, diabetes, chronic lung } \\
\text { disease, congestive heart failure, } \\
\text { non-Hodgkin lymphoma, } \\
\text { mediastinal radiation, right fibro } \\
\text { thorax, delayed sternal closure }\end{array}$ \\
\hline 6 & 16 & Male & $\begin{array}{l}\text { Innominate artery } \\
\text { ligation, multiple open } \\
\text { chest airway } \\
\text { reconstructions }\end{array}$ & $\begin{array}{l}\text { Pseudoaneurysm from } \\
\text { innominate artery } \\
\text { stump }\end{array}$ & Tracheal rupture & Urgent & $\begin{array}{l}\text { Non-Hodgkin lymphoma, mediastina } \\
\text { radiation, trachea-innominate } \\
\text { artery fistula, innominate artery } \\
\text { ligation, multiple airway surgical } \\
\text { reconstructions, extensive } \\
\text { mediastinal fibrosis }\end{array}$ \\
\hline
\end{tabular}

Emergency or urgent status defined according to Society of Thoracic Surgeons guidelines.

\section{RESULTS}

Table 1 summarizes the patient demographic characteristics, preoperative characteristics, and indications for the procedures. The mean age at the time of intervention was $68 \pm 23$ years (16-90 years). Three patients were operated on in emergency or urgent settings: 2 for acute, complicated type A dissection (1 ruptured dissection, 1 cerebral malperfusion) and 1 for innominate artery pseudoaneurysm with rupture into the trachea. The other 3 cases involved pseudoaneurysm formation from previous cardiac surgery ( 2 after coronary artery bypass grafting, 1 after heart and bilateral lung transplant) and underwent elective interventions. All patients were deemed by a multidisciplinary team to face prohibitively high risk with open surgical repair because of multiple cardiothoracic interventions, advanced age, debilitated condition, and comorbidities.
Intraoperative parameters and landing zone information are detailed in Tables 2 and 3. Cardiopulmonary bypass was used in 1 case (innominate artery pseudoaneurysm). Access was obtained through a transfemoral approach in 1 procedure $(17 \%)$, through the left common carotid in 1 procedure $(17 \%)$, and through a transapical approach in 4 procedures $(66 \%)$. Stent-graft dimensions ranged from 22 to $40 \mathrm{~mm}$ in diameter and from 55 to $81 \mathrm{~mm}$ in length. Cook TX2 stent-grafts and extensions (Cook Medical) were used in 5 cases ( 2 dissections, 3 pseudoaneurysms), and an Amplatzer vascular plug (AGA Medical) was used in 1 case (bypass vein graft anastomosis pseudoaneurysm).

For the 2 type A aortic dissection cases (Figure 1), the TX2 distal extension grafts were deployed through a transapical approach. In both cases, proximal endoleaks at the sinotubular junction required proximal deployment of a second TX2 distal extension piece. In 1 case, this achieved

FIGURE 2. Imaging for the patients with ascending aortic pseudoaneurysm (A, B, E, and F), saphenous vein graft pseudoaneurysm after coronary artery bypass grafting $(\mathrm{C}$ and $\mathrm{D})$, and innominate artery pseudoaneurysm $(\mathrm{G}$ and $\mathrm{H})$ is shown. A and $\mathrm{B}$, A patient with a pseudoaneurysm at an aortic crossclamp site; intraoperative angiography before (A) and after (B) ascending stent deployment demonstrates complete occlusion of the pseudoaneurysm. C and D, A patient with an occluded saphenous vein graft and a pseudoaneurysm at the aortic anastomotic site was treated with transfemoral deployment of an Amplatzer vascular plug. E and F, A patient with a heart bilateral lung transplant; a pseudoaneurysm of the aortic anastomosis was treated with transapical deployment of a Zenith TX2 distal extension graft. An aortic model of the preoperative and postoperative ascending aorta is shown. G and H, In a young patient with mediastinal fibrosis and tracheostomy, with an innominate artery pseudoaneurysm after ligation of a tracheoinnominate fistula, left common carotid artery access was used to stent the ascending aorta, with occlusion of the innominate artery stump. 
TABLE 2. Individual intraoperative data

\begin{tabular}{|c|c|c|c|c|c|c|c|}
\hline Patient & Approach & Device used & $\begin{array}{c}\text { No. of } \\
\text { stents used }\end{array}$ & $\begin{array}{c}\text { Stent } \\
\text { length }(\mathbf{m m}) \\
\end{array}$ & $\begin{array}{c}\text { Stent } \\
\text { diameter }(\mathbf{m m}) \\
\end{array}$ & $\begin{array}{l}\text { Proximal } \\
\text { extension } \\
\text { deployed }\end{array}$ & Endoleak \\
\hline 1 & Transapical & Cook Zenith TX2 distal extension & 2 & 77 & 38 & Yes $(77 \times 38)$ & Yes \\
\hline 2 & Transapical & Cook Zenith TX2 distal extension & 1 & 81 & 40 & No & No \\
\hline 3 & Transfemoral & Amplatzer vascular plug & 0 & NA & NA & No & No \\
\hline 4 & Transapical & Cook Zenith TX2 distal extension & 2 & 77 & 38 & Yes $(77 \times 38)$ & No \\
\hline 5 & Transapical & Cook Zenith TX2 distal extension & 2 & 77 & 38 & Yes $(77 \times 38)$ & No \\
\hline 6 & $\begin{array}{l}\text { Left common } \\
\text { carotid artery }\end{array}$ & Cook Zenith EVAR iliac limb extension & 1 & 55 & 22 & No & No \\
\hline
\end{tabular}

NA, Not applicable, EVAR, endovascular aortic repair.

coverage of the tear site (Figure 1, D-F), with resolution of the endoleak. In the second case (a 90-year-old patient), however, the endoleak persisted despite deployment of a proximal extension to the sinotubular junction. Of note, this patient presented with the dissection flap occluding the innominate artery and causing cerebral malperfusion, and endografting successfully expanded the aortic true lumen, restoring innominate perfusion (Figure 1, $A-C$ ); no further endovascular therapy was therefore attempted. In 2 cases with aortic pseudoaneurysm formation, a transapical approach was used to seal the leak (Figure 2, $A, B, E$, and $F$ ); in both cases, adequate landing zones were available that did not impinge on the great vessels or the coronary ostia.

In-hospital and 30-day mortalities were zero (Table 4). There were no coronary complications, no stent-graftrelated complications, and no instances of renal failure. One patient with type A aortic dissection had a left cerebellar stroke, with no residual deficit $(\mathrm{n}=1$; stroke rate of $17 \%$ ). Other complications included prolonged ventilation (ventilation $>24$ hours, $\mathrm{n}=1 ; 17 \%$ ) and proximal endoleak $(\mathrm{n}=1 ; 17 \%)$. Mean hospital stay was $9.5 \pm 3.8$ days (range, 5-15 days), and intensive care unit stay was prolonged in the 2 patients with type A dissection (10 days) relative to those with pseudoaneurysm (mean intensive care unit stay, 1.25 days). Mean follow-up was 33 months (3-57 months). There were no reinterventions. One patient with type A aortic dissection had an ongoing proximal endoleak and died 6 months after the operation

TABLE 3. Intraoperative parameters and landing zones

\begin{tabular}{lc}
\hline \multicolumn{1}{c}{ Landing zone } & $\mathbf{n}=\mathbf{5}$ \\
\hline No. of stents used per case & $1-2$ \\
Extension deployed & $\mathrm{n}=3(66 \%)$ \\
Proximal endoleak & $\mathrm{n}=1(20 \%)$ \\
Distal landing zone & \\
$\quad \begin{array}{l}\text { Proximal to the origin of the innominate artery } \\
\quad \text { Covering the origin of the innominate artery }\end{array}$ & $\mathrm{n}=4(80 \%)$ \\
Proximal landing zone & $\mathrm{n}=1(20 \%)$ \\
$\quad$ Sinotubular junction & $\mathrm{n}=5(100 \%)$ \\
\hline
\end{tabular}

of Pseudomonas pneumonia. The second patient treated for type A aortic dissection, despite having a satisfactory postoperative computed tomographic angiography, had an endoleak develop at 12 months; she remained alive without progression of pathology. There was 1 additional death of a non-aorta-related cause; this patient died of progressive ischemic cardiomyopathy 27 months after the operation.

\section{DISCUSSION}

Our experience demonstrates that endovascular repair of the ascending aorta is technically feasible and can be accomplished with promising early results. Despite extensive comorbidities and significant anatomic challenges, the in-hospital and 30-day mortalities were zero among these patients, with only 1 technical failure. Other aortic centers of excellence have also reported small series of endovascular repair of the ascending aorta with similar results. ${ }^{1-14}$ Generally, worldwide experience has been limited by multiple factors, including anatomic constraints of the proximal aorta, the lack of devices specifically designed for the ascending aorta, and the lack of disease-specific stent-graft technologies.

The technical creativity required to treat the patients in our series highlights the current obstacles to the treatment of ascending aortic pathologies with the current endovascular stent-graft platforms. Currently available systems were primarily designed for the descending thoracic and

TABLE 4. Summary of postoperative outcomes

\begin{tabular}{lc}
\hline In-hospital or 30-d mortality & 0 \\
Stroke & $\mathrm{n}=1(17 \%)$ \\
Paraplegia or paraparesis & 0 \\
Myocardial infarction & 0 \\
Renal failure & 0 \\
Prolonged ventilation & $\mathrm{n}=1(17 \%)$ \\
Intensive care unit stay (days, mean $\pm \mathrm{SD})$ & $4.2 \pm 4.3$ \\
Hospital stay (days, mean $\pm \mathrm{SD})$ & $9.5 \pm 3.8$ \\
Endoleak & $\mathrm{n}=1(17 \%)$ \\
Stent-related complications & 0 \\
\hline$S D$, Standard deviation. &
\end{tabular}


abdominal aorta and do not address ascending aortic anatomy and pathology. First, the delivery systems are often too short to reach the proximal aorta from the femoral artery. Second, current thoracic endografts are too long for the length of the ascending aorta, averaging between 7 and $8 \mathrm{~cm}$. Third, the curvature of the arch, encompassing nearly a $270^{\circ}$ arc from the descending thoracic aorta into the aortic root, often cannot be successfully negotiated with current systems designed for the relatively straight distal thoracic and abdominal aorta.

Alternative, nonfemoral approaches have proved to be a creative and successful adaptation in the endovascular treatment of the ascending aorta. We found that the antegrade, transapical approach addresses many of the limitations of the current technology. First, the transapical approach addresses the issues of inadequate femoral artery access. Second, the transapical approach addresses the inadequate length of current delivery systems, which are too short to reach the ascending aorta through a femoral approach in tall patients or patients with tortuous aortoiliofemoral vasculature. Third, the antegrade approach avoids the issues of retrograde passage across the curvature of the ascending aorta and eliminates the issue of endograft conformability to the arch. Finally, for pathologies such as aortic dissection, the antegrade approach may provide the quickest and most reliable access into the true lumen. In patients with multiple tears and fenestrations, a retrograde approach from the femoral artery may hinder deployment of the stent-graft in the true lumen. When using an antegrade approach with devices designed for retrograde deployment, however, one must consider that the endograft will deploy distally to proximally, potentially compromising precise placement at the proximal landing zone.

The creative use of thoracic endograft extension components in our series further highlights the fact that the current thoracic endograft devices are often too long. The shortest main body for all 4 of the currently Food and Drug Administration-approved thoracic endografts is $10 \mathrm{~cm}$. Because the average length of the ascending aorta is 7 to $8 \mathrm{~cm}$, coverage with these devices of the coronary arteries proximally and of the innominate artery distally is quite likely. In our series, stent-graft extensions for thoracic endografts (Zenith TX2 distal extension) with a 77-mm treatment length were used in 4 cases, and an EVAR iliac limb was used in 1 case.

Most patients in our series were treated for pseudoaneurysm of the ascending aorta. With the current technology, pseudoaneurysm will likely remain the lesion most amendable to endovascular repair, because the focal nature of the lesion often results in adequate proximal and distal landing zones. To treat more common lesions, however, such as aortic dissection and aneurysms, adaptation of the devices will be needed to address the proximal and the distal landing zones. In the 2 patients with type A aortic dissection, the proximity of the tear site to the sinotubular junction and coronary ostia and the aortic curvature at the level of the sinotubular junction and aortic root complex made achievement of an endograft seal challenging. For aneurysmal disease, the lack of adequate landing zones at the sinotubular junction and at the innominate artery may prove prohibitive.

Improvement in stent-graft design is desperately needed before broader application to ascending aortic pathologies can be achieved. Devices with shorter length and delivery systems with conformability to the arch must be designed. Innovative design modifications might include a valve component, extending the proximal landing zone to the aortic valve annulus, and a side branch to the innominate artery, extending the distal landing zone to the origin of the left common carotid artery. Maintaining coronary perfusion might involve disruptive technology, such as a multilayer flow modulator, for endovascular treatment to be applied to the aortic root. ${ }^{15}$

Finally, appropriate patient selection in the management of ascending aortic pathologies remains of utmost importance. We must be aware that an open surgical approach remains the criterion standard, yielding excellent contemporary results. Until improved technology is available, only the patients at highest or even otherwise prohibitive risk should undergo endovascular repair of the ascending aorta with the current, inadequately designed, endografts.

\section{References}

1. Szeto WY, Fairman RM, Acker MA, Skelly CL, Augoustides JG, McGarvey M, et al. Emergency endovascular deployment of stent graft in the ascending aorta for contained rupture of innominate artery pseudoaneurysm in a pediatric patient. Ann Thorac Surg. 2006;81:1872-5.

2. Preventza O, Henry MJ, Cheong BY, Coselli JS. Endovascular repair of the ascending aorta: when and how to implement the current technology. Ann Thorac Surg. 2014;97:1555-60.

3. Ronchey S, Serrao E, Alberti V, Fazzini S, Trimarchi S, Tolenaar JL, et al. Endovascular stenting of the ascending aorta for type A aortic dissections in patients at high risk for open surgery. Eur J Vasc Endovasc Surg. 2013;45: 475-80.

4. Metcalfe MJ, Karthikesalingam A, Black SA, Loftus IM, Morgan R, Thompson MM. The first endovascular repair of an acute type A dissection using an endograft designed for the ascending aorta. J Vasc Surg. 2012;55: 220-2.

5. Szeto WY, Moser WG, Desai ND, Milewski RK, Cheung AT, Pochettino A. Transapical deployment of endovascular thoracic aortic stent graft for an ascending aortic pseudoaneurysm. Ann Thorac Surg. 2010;89:616-8.

6. Kolvenbach RR, Karmeli R, Pinter LS, Zhu Y, Lin F, Wassiljew S. Endovascular management of ascending aortic pathology. J Vasc Surg. 2011; 53:1431-8.

7. Mussa FF, LeMaire SA, Bozinovski J, Coselli JS. An entirely endovascular approach to the repair of an ascending aortic pseudoaneurysm. J Thorac Cardiovasc Surg. 2007;133:562-3.

8. Shabaneh B, Gregoric ID, Loyalka P, Krajcer Z. Complex endovascular repair of a large dissection of the ascending aorta in a 70-year-old man. Tex Heart Inst $J$. 2013;40:182-5.

9. Coscas R, Javerliat I, Tofigh AM, Hebert T, Jablonski M, Cluzel P. Pseudoaneurysm of a saphenous bypass treated with covered endograft in the ascending aorta. J Thorac Cardiovasc Surg. 2007;134:230-2. 
10. Uchida K, Imoto K, Yanagi H, Machida D, Okiyama M, Yasuda S. Endovascular repair of ascending aortic rupture: effectiveness of a fenestrated stent-graft. J Endovasc Ther. 2010;17:395-8.

11. Yang ZH, Xia LM, Wei L, Wang CS. Complications after endovascular repair of Stanford type A (ascending) aortic dissection. Eur J Cardiothorac Surg. 2012;42: 894-6.

12. Spear R, Kaladji A, Roeder B, Haulon S. Endovascular repair of a chronic arch dissecting aneurysm with a branched endograft. Ann Thorac Surg. 2013;96: e39-41.
13. Pasic M, Zipfel B, Drews T, Dreysse S, Unbehaun A, Buz S, et al. Transapical placement of an uncovered aortic endostent for type a aortic dissection. Circ Cardiovasc Interv. 2011;4:e49-53.

14. Pires de Morais G, Rodrigues A, Gama V. Treatment of type-A aortic dissection using endoprosthesis occurring after coronary artery bypass surgery. Catheter Cardiovasc Interv. 2012;80:1099-104.

15. Sultan S, Hynes N. One-year results of the multilayer flow modulator stent in the management of thoracoabdominal aortic aneurysms and type B dissections. J Endovasc Ther. 2014;20:366-77. 